\title{
EL DERECHO DE INFANCIA VISTO DESDE EL CAMPO Y HABITUS JURÍDICO*
}

\author{
THE CHILDHOOD LAW SEEN FROM \\ THE LEGAL CAMPUS AND HABITUS
}

\author{
Aroldo Quiroz Monsalvo** \\ Fecha de recepción: 15 de agosto de 2013 \\ Fecha de aprobación: 20 de noviembre de 2013 \\ Disponible en línea: 30 de junio de 2014
}

\section{Para citar este artículo / To cite this article}

Aroldo Quiroz Monsalvo, El derecho de infancia visto desde el campo y habitus jurídico, 128 Vniversitas Jurídica (2014). http://dx.doi.org/10.11144/ Javeriana.VJ128.divd

doi:10.11144/Javeriana.VJ128.divd

* El presente artículo es producto de la investigación que se viene desarrollando dentro de la línea investigativa "El nuevo derecho de familia", en la Facultad de Derecho de la Universidad Santo Tomás, sede Bogotá. Estas categorías de análisis fueron creadas por el filósofo francés Pierre Bourdieu.

** Discípulo del Doctorado en Derecho de la Universidad Santo Tomás de Bogotá. Magíster en Derecho de la Facultad de Derecho, Ciencias Políticas y Sociales de la Universidad Nacional, con posgrado en Instituciones Jurídicas Familiares de la misma Universidad; actualmente, director del Área de Derecho Privado de la Universidad Santo Tomás, profesor de las Facultades de Derecho de las universidades Santo Tomás, Sinú, Nacional, Andes y Libre de Bogotá. Correo electrónico: quiroz41@hotmail.com 


\section{RESUMEN}

La disertación muestra la lucha que libran académicos, abogados, jueces y cortes - aquí denominados agentes jurídicos - por imponer conceptos del derecho de infancia; cómo a través de sus discursos van legitimando la producción e interpretación del corpus juris en el campo jurídico del derecho de infancia, esto es, las reglas y principios de los derechos de los niños; y cómo tales discursos se convierten en habitus que la organización social interioriza y repite de generación en generación, convirtiéndolos en verdades jurídicas y en propuestas para solucionar la vulneración de los derechos de los niños y niñas en Colombia.

Palabras clave: infancia; campo jurídico; habitus; agentes; Sistema Nacional de Bienestar Familiar; políticas públicas 


\section{ABSTRACT}

The dissertation shows the struggle academics, lawyers, judges and courts sort out -here called legal agents - to impose law concepts of childhood; how through the different speeches they try to legitimate the production and interpretation of the corpus juris in the legal field of childhood law, considering the rules and principles of the rights of children; and how such discourses become habitus internalized by the society and repeated from generation to generation, making them legal truths and proposals to remedy the violation of the rights of children in Colombia.

Keywords: childhood; campus; habitus; agents; public policies

\section{SUMARIO}

INTRODUCCIÓN.- METODOLOGÍA.- MARCO TEÓRICO.- I. EL CAMPO JURÍDICO Y EL EJERCICIO DE LOS DERECHOS DE LOS NIÑOS.- II. LOS AGENTES DEL CAMPO JURÍDICO Y EL DERECHO DE INFANCIA.- CONCLUSIONES. 


\section{INTRODUCCIÓN}

La investigación está enmarcada en el enfoque de la sociología jurídica y tiene como objeto de estudio los derechos de la infancia desde el punto de vista externo'; de ahí que dichos derechos se analizarán dentro de un contexto social.

Para abordar el estudio desde lo sociológico se tuvo como base teórica la construcción de análisis del campo jurídico que hace el filósofo francés Pierre Bourdieu ${ }^{2}$, en el cual muestra cómo los académicos y juristas construyen y convierten sus discursos en verdades jurídicas, y a partir de allí libran una lucha por imponerlos en un espacio que el profesor Bourdieu denomina campo jurídico. Desde ese enfoque se quiere evidenciar cómo se construye el discurso del derecho de infancia en Colombia, cómo lo asimila la organización social y cómo se comportan los agentes jurídicos en el mencionado campo jurídico. Para comprender el fenómeno se tomó como punto de observación el Sistema Nacional de Bienestar Familiar ${ }^{3}$, sistema encargado de garantizar y restablecer los derechos de los niños en el país.

La pertinencia del presente estudio está en mostrar cómo los agentes jurídicos han construido la teoría de los derechos de los niños en Colombia y cómo estos siguen siendo una noción simbólica a pesar de contar con un cuerpo jurídico que los consagra.

\section{METODOLOGÍA}

La presente investigación utiliza el método empírico, combinando la experiencia y la teoría, a partir de la observación de los derechos de los niños, que es el objeto previsto. En consecuencia, se hace una descripción analítica encuadrando cada una de las partes con que se construyen los discursos y nacen nuevos procesos, instituciones y se expiden códigos con base en estos.

El estudio está estructurado en dos partes: la primera se centra en cómo se van construyendo los discursos teóricos sobre los derechos

1 Rafael Hernández Marín, Introducción a la teoría de la norma jurídica, $2^{\mathrm{a}}$ ed, Marcial Pons, Ediciones Jurídicas y Sociales S.A., Madrid (2002).

2 Ibídem.

3 Colombia. Departamento Administrativo de la Prosperidad Social. Decreto 0936 del 9 de mayo de 2013. 
de los niños en el campo jurídico; la segunda muestra el número de agentes, incluidos los del derecho comparado, que participan en la lucha por imponer su poder (conceptos) en el campo jurídico, y cómo tales concepciones son apropiadas por el cuerpo social hasta convertirlas en un habitus.

\section{MARCO TEÓRICO}

En Colombia los derechos de la infancia, hoy positivados en el Código de la Infancia y la Adolescencia, así como en diferentes instrumentos y convenios internacionales ratificados por el Estado, han sido y siguen siendo objeto más de una lucha por imponer discursos que por hacerlos efectivos en su ejercicio. Desde un punto de vista externo, se observa un campo en donde agentes e instituciones libran verdaderas batallas por el monopolio de qué es el derecho de infancia; en esa lucha, los agentes jurídicos productores (autores y académicos, por ejemplo) y los intérpretes del derecho (jueces o defensores de familia), imponen discursos tendientes no solo a acumular la mayor cantidad de capital jurídico ${ }^{4}$, lo que permite mostrar una división del trabajo jurídico ${ }^{5}$, en el cual se evidencian nuevas leyes, jurisprudencias, procesos, instituciones, ONG, fechas conmemorativas, sin que con ello se logre la efectividad en el ejercicio de los derechos de los niños, que, por el contrario, siguen siendo objeto de vulneración constante.

Para mostrar tal lucha se parte de un marco teórico basado en las nociones de campo jurídico, habitus y agentes, desarrolladas por Pierre Bourdieu6. Por campo jurídico se entenderá, entonces, el espacio estratégico donde se indagarán los siguientes aspectos: producción jurídica: relaciones entre las diferentes categorías de juristas, académicos y magistrados; procesos y reglas: discursos, relaciones del derecho con otras ciencias sociales.

Por habitus debe comprenderse el proceso por el cual los individuos interiorizan y asumen como ciertos los discursos jurídicos socializados y legitimados a través de leyes o normas y por nuevas

4 Álvaro Moreno Durán \& José Ernesto Ramírez, Sociología del campo jurídico en Colombia: relaciones y perspectivas, Universidad Santo Tomás, Bogotá (2011).

5 Ibídem.

6 Ibídem. 
ciencias que nacen en el campo; por agentes, los especialistas en la producción del derecho, a los cuales se debe, según Moreno y Ramírez ${ }^{7}$, la consagración de la existencia del campo jurídico y el reconocimiento de los expertos — juristas, académicos, políticos, legisladores, funcionarios públicos y abogados - y su rol específico dentro del mencionado campo.

Bajo este enfoque teórico se describe, en la práctica, cómo se van construyendo los discursos de los derechos de los niños contenidos en el Código de la Infancia y la Adolescencia y que, por lo tanto, se muestran como un capital simbólico.

\section{EL CAMPO JURÍDICO Y EL EJERCICIO DE LOS DERECHOS DE LOS NIÑOS}

El campo jurídico en el que se desenvuelven los derechos de los niños está compuesto por un ordenamiento jurídico ${ }^{8}$ conformado por una Constitución Política que legitima tales derechos ${ }^{9}$; y un Código ${ }^{10}$ donde se estatuye que estos serán materializados a través de una política pública de infancia y adolescencia ${ }^{11}$, política que estará a cargo del Estado ${ }^{12}$.

Se muestran en campo tales cuerpos jurídicos con reglas de tipo coactivo que presionan a los agentes del Estado integrantes del Sistema Nacional de Bienestar Familiar (en adelante el Sistema) como cumplidores de la garantía de los derechos. Por otra parte, en el campo concurren otras ciencias como la estadística que muestra como la tasa de mortalidad infantil es del $17,78 \%$ de mil nacidos vivos $^{13}$ y como 2.459 niños de 0 a 5 años fueron víctimas de maltrato infantil en el año $2012^{14}$.

\footnotetext{
7 Álvaro Moreno Durán \& José Ernesto Ramírez, óp. cit., 47.

8 José Juan Moreso \& Pablo Eugenio Navarro, Orden jurídico y sistema jurídico: una investigación sobre la identidad y la dinámica de los sistemas jurídicos, Centro de estudios constitucionales, Madrid (1993).

9 Colombia. Constitución Política, artículo 44.

10 Colombia. Ley 1098 de 2006, Código de la Infancia y la Adolescencia.

11 Ibídem, artículo 204.

12 Ibídem, artículo 10.

13 Fondo de las Naciones Unidas para la Infancia, "Algunos ejemplos de indicadores sobre: ciclo vital". Disponible en www.sinfoniaunicef.info/category/ciclo-vital/ (Consultado el 28 de marzo del 2014).

14 Ibídem.
} 
Se observa como en el campo, con las reglas contenidas en estos cuerpos jurídicos y las cifras de las estadísticas, los agentes ${ }^{15}$ libran una lucha en la construcción de discursos sobre los derechos de los niños ${ }^{16}$ que les representen reconocimiento como expertos ${ }^{17}$. Eso explica la cantidad de propuestas que rivalizan por mostrar su pertinencia frente a la garantía y restablecimiento de los derechos de la infancia y adolescencia, algunas de las cuales se plasman en normas positivas como, por ejemplo, el artículo 204 del Código de la Infancia, que consagra que los alcaldes están obligados a elaborar políticas públicas de infancia, y el artículo 205 ibídem, que establece que el Sistema Nacional de Bienestar Familiar prestará el servicio para que estas se materialicen.

Con tales reglas se muestra en el campo, como en Colombia los niños son personas jurídicas ${ }^{18}$ titulares de derechos fundamentales que son garantizados por el Estado, y que los niños pueden ejercer como ciudadanos $^{19}$; por lo tanto, se evidencia en el campo la dimensión iusfundamental de los derechos ${ }^{20}$.

De otra parte, en la lucha por imponer conceptos y mostrar cumplimiento de los derechos, en el discurso de todas las entidades estatales en materia de política pública de infancia se pone de presente la obligación positiva progresiva para el Estado, la cual, parafraseando a Rousseau, se sustenta en las obligaciones del contrato social ${ }^{21}$ y la legitiman con la comunidad internacional ${ }^{22}$. En este discurso se muestra como el contrato contiene la obligación del Estado, ante los organismos internacionales, de garantizar, promover y vigilar el cumplimiento de los derechos humanos de los niños, lo que le implica adoptar, a nivel interno, todas las medidas de carácter administrativo, legislativo y de cualquier otra índole para dar cumplimiento a los derechos contenidos en la Convención

15 Álvaro Moreno Durán \& José Ernesto Ramírez, óp. cit., 47.

16 Carlos Tejeiro López, Teoría general de niñez y adolescencia, Universidad de los Andes, Bogotá (2005).

17 Inés M. Weinberg, Convención sobre los derechos delniño, Rubinzal-Culzoni Editores, Buenos Aires (2002).

18 Colombia. Constitución Política, artículo 14. "Toda persona tiene derecho al reconocimiento de su personalidad jurídica".

19 Colombia. Código de la Infancia y la Adolescencia, artículo 25.

20 Ricardo Guastini, Distinguiendo: estudios de teoría y metateoría del derecho, Jordi Ferreri Beltrán (trad.), Editorial Gedisa, Barcelona (1999).

21 Jean Jacques Rousseau, El Contrato Social, Editoriales S.A., Madrid (1983).

22 Ejemplo, Unicef. 
sobre los Derechos del Niño ${ }^{23}$ y otros tratados internacionales debidamente ratificados. El discurso, pues, reivindica los derechos de la infancia ${ }^{24}$, los cuales son positivados e interiorizados por el órgano social y la comunidad académica experta en el tema.

La comunidad internacional también juega un papel en el campo jurídico de los derechos de los niños ${ }^{25}$, que radica en demandar informes estatales respecto a su cumplimiento, con base en los convenios, pactos y tratados, a saber: la Declaración de los Derechos Humanos ${ }^{26}$, la Declaración de los Derechos del Niño ${ }^{27}$, el Pacto de San José de Costa Rica ${ }^{28}$, el Pacto de los Derechos Civiles y Políticos ${ }^{29}$, el Pacto de los Derechos Sociales, Económicos y Culturales ${ }^{30}$ y la Declaración de Naciones Unidas "Un mundo más justo para los niños y las niñas", lo que legitima simbólicamente el cumplimiento por parte del Estado.

Tales compromisos internacionales respecto al cumplimiento de los derechos de la infancia muestran en el campo a los actores políticos expidiendo normas internas convertidas en instrumentos simbólicos ${ }^{31}$. Así, el campo jurídico nacional se ha visto abonado con reformas legislativas como la Ley 75 de 1968, que crea el Instituto Colombiano de Bienestar Familiar (ICBF); la Ley 7 de 1979 que instituye el Sistema Nacional de Bienestar Familiar (SNBF); el Decreto 2737 de 1989 por el cual se expide el Código del Menor y la Ley 1098 del 2006, por el cual se expide el Código de la Infancia y la Adolescencia.

Estas reformas generan en el campo jurídico, como lo señala Bourdieu, citado por Moreno y Ramírez, un capital simbólico ${ }^{32}$ que crea en el imaginario colectivo la ilusión de cumplimiento de las garantías de los derechos de los niños por parte del Estado;

23 Artículo 4.

24 Emilio García Méndez, Infancia, ley y democracia: una cuestión de justicia, Editorial Temis - Ediciones Depalma, Bogotá - Buenos Aires (1998).

25 Ligia Galvis Ortiz, Las niñas, los niños y los adolescentes "titulares activos de derechos", Ediciones Aurora, Bogotá (2006).

26 Artículo 11.

27 Artículo 1.

28 Artículo 5-5.

29 Artículo 10-2-b-3.

30 Artículo 10-3.

31 Mauricio García Villegas \& César Rodríguez, Derecho y sociedad en América Latina: un debate sobre los estudios jurídicos críticos, Editorial ILSA - Universidad Nacional de Colombia, Bogotá (2003).

32 Álvaro Moreno Durán \& José Ernesto Ramírez, óp. cit., 42. 
sin embargo, en el campo se evidencia que en el año 2007 fueron abusados en Colombia 19.617 niños entre 0 a 17 años de edad, y en el año 2012 fueron madres 6.270 niñas entre 10 a 14 años de edad ${ }^{33}$, situación que se mantiene hasta la fecha. Este panorama hace que en el campo los agentes sean capaces de replantear objetivos y estrategias sobre la marcha, utilizando los efectos imprevistos para erigir nuevos fines que no estaban contemplados inicialmente. Es así como pasamos del Código del Menor (Decreto 2737 de 1989) al Código de la Infancia y Adolescencia (Ley 1098 del 2006).

El campo jurídico, a su vez, se relaciona con otras ciencias como la economía, en la que, entre otras, se evidencia de qué manera la desigualdad en la distribución de los ingresos de las personas afecta negativamente el desarrollo humano y, por consiguiente, a la infancia y la adolescencia. Por ejemplo, el índice de Gini muestra cómo, en el país, la desigualdad en la distribución del ingreso pasó de 0,544 en 1996 a 0,563 en 2003 y como, cuando se realiza la corrección por distribución de ingresos, el Índice de Desarrollo Humano (IDH) se reduce en cerca de 13 puntos, es decir, un retroceso de más de 15 años $^{34}$, desigualdad que se presenta en todos los frentes.

El discurso estadístico señala también la amplia brecha entre las zonas rural y urbana. Mientras la zona urbana se acerca a los índices de países latinoamericanos clasificados como de alto desarrollo - Uruguay y México, puestos 52 y 40, respectivamente-las áreas rurales tienen niveles similares a países de desarrollo medio como Vietnam, que se ubica en el puesto $109^{35}$. Esta desigualdad se refleja en la tasa de analfabetismo, que en el sector rural es cuatro veces superior a la urbana (16\%), pues mientras en la zona rural de cada 100 personas en edad escolar 40 no asisten a un centro educativo, en la zona urbana no asisten unos $28^{36}$. Por departamentos, en Colombia, el Chocó, Cauca y Nariño se mantienen como los entes territoriales con menor desarrollo humano en los últimos catorce años, en tanto que en el extremo opuesto encontramos a Bogotá

33 Unicef, óp. cit. Disponible en: www.sinfoniaunicef.info/category/ciclo-vital

34 Sistema de las Naciones Unidas y CePAL. Programa Nacional de Desarrollo Humano DNP/ PNUD - Agencia Colombiana de Cooperación Internacional - Federación Colombiana de $\mathrm{Mu}$ nicipios y Cooperación Técnica Alemana GTZ, Las regiones colombianas frente a los objetivos del milenio, Autores, Bogotá (2004).

35 Ibídem.

36 Ibídem, 17. 
y Atlántico. En los años noventa el Valle del Cauca, Antioquia y Santander lograron avances considerables hasta ubicarse entre los departamentos con mayores niveles de desarrollo humano ${ }^{37}$.

Igualmente, el campo jurídico se relaciona con las ciencias que estudian la violencia en Colombia ${ }^{38}$, cuyos discursos visibilizan la desprotección en que han quedado los niños, niñas y adolescentes afectados por este flagelo y ponen de presente las causas que la generan.

De lo anterior se concluye que el campo jurídico de los derechos de la infancia se convierte en espacio estratégico construido a partir de los discursos de los agentes, que legitiman códigos, leyes, procesos, entidades, sistemas, ciencias, y se parte de la base de que por sí solos garantizan y restablecen los derechos de los niños y adolescentes. Por otra parte, se muestran relaciones de fuerza entre los agentes y entre grupos ${ }^{39}$, reinventando procesos y discursos.

A continuación se presenta la lucha entre los agentes que han construido los discursos positivizados de los derechos de los niños, ilustrada con casos prácticos.

\section{LOS AGENTES DEL CAMPO JURÍdico Y EL DERECHO DE INFANCIA}

El campo jurídico es el escenario en el cual los agentes son especialistas en la producción del derecho de infancia y donde se libran las más encarnizadas luchas por imponer los conceptos y abrirse los espacios para consagrarse como expertos ${ }^{40}$ en derechos de infancia. En consecuencia, el campo será para los agentes el "escenario donde las controversias teóricas y los debates académicos no se reducen a la lucha por la conquista o la defensa de un magisterio intelectual. Sino que se presentará como un espacio polarizado por las relaciones de poder, o por el poder" 41 .

\footnotetext{
37 Ibídem, 18.

38 Fabio Sánchez, Las cuentas de la violencia. Ensayos económicos sobre el conflicto y el crimen en Colombia, Editorial Norma, Bogotá (2007).

39 Álvaro Moreno Durán \& José Ernesto Ramírez, óp. cit., 48.

40 Ibídem, óp. cit., 47.

41 Ibídem.
} 
Para describir lo enunciado se presentan casos prácticos enmarcados en el método de análisis social ${ }^{42}$, que es el que viene utilizando la noción de campo y espacio social en el derecho de infancia. Por lo tanto, a través de estos se mostrará el espacio polarizado de las relaciones de poder por el poder de los agentes.

En el campo de la infancia, se dijo, concurren una serie de actores, agentes, instituciones ${ }^{43}$, procesos, etcétera, que compiten por apropiarse de los productos específicos que se encuentran en disputa de acuerdo con las reglas contenidas en el Código de Infancia, v. gr., contratos para atención a los niños, tráfico de influencias, consultorías, entre otros, mientras se olvida la esencia de los derechos de la infancia que contiene el Código.

En esta lógica, el primero en aparecer en el campo jurídico es el Sistema Nacional de Bienestar Familiar ${ }^{44}$ (ente simbólico), como escenario donde se dan las controversias teóricas y los debates académicos entre expertos que tratan de imponer su magisterio intelectual en un espacio polarizado por las relaciones de poder. Aquí se destacan las altas cortes, jueces, fiscales, defensores de familia, comisarios de familia, académicos y abogados, quienes se enfrentan permanentemente por sus ideas sobre la forma de entender y aplicar el derecho de infancia ${ }^{45}$. En esa lucha intelectual por conceptualizar y establecer qué es el derecho de infancia se resalta la discusión sobre la prevalencia de los derechos de los niños, como se destaca en el artículo 44 inciso final de la Carta Política y el artículo 9 del Código de la Infancia que consagra que "en todo acto, decisión o medida administrativa, judicial o de cualquier naturaleza que deba adoptarse en relación con los niños, las niñas y los adolescentes, prevalecerán los derechos de estos, en especial si existen conflictos entre sus derechos fundamentales con los de cualquier otra persona".

Veamos un ejemplo ${ }^{46}$ : en el año 2008 en Colombia se conoció una controversia bastante interesante en la jurisdicción de fami-

42 Bourdeau, óp. cit., 155 y ss.

43 Eduardo Bustelo, El recreo de la infancia: argumentos para otro comienzo, Siglo Veintiuno Editores, Buenos Aires (2007).

44 Espacio donde concurren todas las entidades del Estado que tienen competencia para garantizar y restablecer los derechos de los niños. Véanse artículos 2 y 7 del Decreto 0936 de 2013.

45 Colombia. Corte Constitucional. Sentencia T-968 de 2009. En ella se evidencia una batalla en el campo jurídico, entre autoridades administrativas y judiciales en relación con un niño, en un caso de arrendamiento de vientre.

46 Para salvaguardar el derecho a la intimidad de las partes se omiten los apellidos. 
lia en el circuito judicial de Bogotá. Se debatía en ese entonces el derecho fundamental de la filiación de una menor de edad, y el desconocimiento que de dicho derecho hace el padre de aquella menor ${ }^{47}$. Resulta que el señor Diego, padre de la menor, agobiado por el ultraje, la injuria y traición de su compañera Jenny, en el año 2008 inició un proceso de impugnación contra la paternidad de la pequeña Karen, a quien había reconocido como su hija hacía más de dos años. De esta situación conoció el Juzgado Noveno de Familia de Bogotá, que en desarrollo del proceso ordenó la práctica de la prueba de ADN, con resultado negativo. Con fundamento en tal prueba, el juez profirió sentencia a su favor, declarando que él no era el padre extramatrimonial de la menor.

Tal sentencia es apelada y la conoce en segunda instancia el Tribunal del Distrito Superior de Bogotá, Sala de Familia, quien la revoca por considerar que la acción instaurada por el señor Diego había caducado, al no haber sido ejercida dentro de los ciento cuarenta (140) días siguientes a aquel en que tuvo conocimiento de que no era el padre de Karen, tal como lo prescribe el artículo 216 del Código Civil Colombiano, desestimando así la prueba de ADN que indicaba otra realidad.

¿Qué fue lo que pasó para que el Tribunal llegara a tal decisión? Que la pareja Diego y Jenny mantuvo unión marital entre los años 2001 y 2004. En octubre del 2004, Jenny tomó la decisión de abandonar el hogar para iniciar una relación sentimental con el señor Néstor, la cual se prolongó hasta el 24 de diciembre del 2004, cuando regresó de nuevo con Diego. A mediados de febrero del 2005, Jenny abandona otra vez su hogar y le cuenta a Diego que se encuentra en embarazo, estado que se desarrolló naturalmente hasta septiembre de ese año, cuando nació la niña Karen.

Presentada la anterior situación, el Tribunal partió del supuesto de que, si el nacimiento se produjo en septiembre del 2005, se colegía que Diego tenía conocimiento objetivo de que la pequeña Karen no podía ser su hija; para cualquier persona inteligente podría surgir la duda de que, si la madre de la niña tuvo "una relación sentimental con Néstor" ocho o nueve meses antes del parto, bien podía ser este el padre de la criatura, circunstancia que dio lugar a que el Tribu-

47 Colombia. Corte Constitucional. Sentencia T-071 de 2012. 
nal sostuviera que Diego podía inferir que no era el padre y que a partir de esta deducción, contaba con el término para impugnar la paternidad, o por lo menos desde la fecha en que reconoció a Karen como su hija, y no venir dos años después a dar inicio a tal acción de impugnación, asegurando así el Tribunal entonces el derecho de filiación paterna de Karen, que le da la ley sustancial y procesal.

Conmovido por tal situación, Diego interpone entonces una acción de tutela contra la decisión del Tribunal, la cual conoció la Sala Civil de la Corte Suprema de Justicia, quien la negó alegando que las apreciaciones del Tribunal eran razonables y que el mero disentimiento del accionante con el resultado del litigio no era suficiente para desconocerla, porque la hermenéutica está basada en la aplicación del artículo 216 del Código Civil y, por lo tanto, la acción de impugnación había caducado para Diego.

La sentencia de tutela llegó para revisión a la Corte Constitucional, corporación que la revocó y concedió el derecho a Diego, desconociendo el derecho fundamental de la filiación de la niña Karen y señalando que no aceptar la prueba de ADN y considerarla irrelevante era alterar el entendimiento del "interés actual", a efectos de actualizar la oportunidad para impugnar la paternidad y conducir a la configuración de lo que, en la teoría del derecho, se conoce como "laguna axiológica", en tanto resuelve el caso sin tener en cuenta una propiedad fáctica sumamente relevante, que amerita sin embargo una decisión jurídica distinta ${ }^{48}$. En consecuencia, según la Corte, debe prevalecer la verdad científica sobre la verdad formal.

La Corte Constitucional, en su lucha por imponer su concepto en el campo jurídico, partió de definir en qué consiste una "laguna axiológica"; prescribió que cuando no se toma en cuenta un hecho sumamente relevante (la contundencia de la verdad científica) al interpretar una ley, generalmente válida, esa laguna amenaza derechos fundamentales del tutelante adulto; en estos casos, debe buscarse una interpretación distinta que la colme. En este juicio en particular, puede lograrse si se entiende de un modo distinto el "interés actual". Si el accionante decide finalmente impugnarla con

48 Carlos Santiago Nino, Fundamentos de derecho constitucional, Editorial Astrea, Buenos Aires, 94 y 95 (2005), citado por la Corte: "Las lagunas axiológicas 'son aquellas situaciones en que si bien el sistema jurídico le asigna una solución al caso en cuestión, no toma como relevante una propiedad que tiene ese tipo de casos y que debería ser relevante para asignarle una solución diferente",. 
fundamento en esas mismas dudas, y lo hace pocos días después de tener certeza sobre la realidad de la filiación, gracias a una prueba como la de ADN, entonces el "interés actual" o bien se presume, o bien no se presume pero se entiende actualizado gracias a la novedad de la prueba científica ${ }^{49}$.

El ejemplo demuestra cómo se da el enfrentamiento entre cortes por imponer su conocimiento del campo jurídico, puesto que el derecho de filiación paterna de Karen quedó sin definir, arrebatado por el concepto jurídico impuesto por uno de los agentes del sistema llamado a protegerla, según los artículos 44 de la Constitución Política y 9 del Código de Infancia.

Otro ejemplo de esta lucha en el campo jurídico de la prevalencia de los derechos de los niños es la sostenida en el año 2006 entre una autoridad administrativa (el ICBF a través de su defensor de familia) y otra judicial (el Juzgado Segundo de Familia de Bogotá), en la que el señor Javier demanda la impugnación de la paternidad de su hijo $\mathrm{XXX}^{50}$ por no haber consentido la inseminación de su esposa Janeth ${ }^{51}$.

El caso es el siguiente: Javier y Janeth, madre del menor XXX, celebraron matrimonio en septiembre de 1998, mantuvieron vida conyugal hasta marzo del 2006 cuando, de común acuerdo, decidieron separarse de cuerpos e iniciar un proceso de divorcio. Durante mucho tiempo la pareja Javier-Janeth trató de concebir un hijo, pero le fue imposible debido a que médicamente Javier padecía de una deficiencia de espermatozoides, posible de superar solo mediante el seguimiento de un tratamiento médico. Esto llevó a la pareja conyugal a estudiar otras opciones, una de ellas la inseminación artificial, llegando a concluir que si Javier no podía concebir, Janeth se inseminaría con esperma del señor Alberto, suegro de Janeth.

Por el destino de la vida los citados esposos, militares de profesión, fueron trasladados a laborar en sedes diferentes al domicilio del hogar; la señora Janeth, a quien embargaba la tristeza por no tener un hijo, procedió sin el consentimiento de su compañero al tratamiento de la inseminación artificial en el Hospital Militar. Quedó embarazada

\footnotetext{
49 Colombia. Corte Constitucional. Sentencia T-071 de 2012.

50 Ver nota de pie de página 50.

51 Colombia. Corte Suprema de Justicia, Sala Civil. Sentencia del 28 de febrero de 2013, exp. 11001-3110-002-2006-00537-01.
} 
y en noviembre del 2004 nació el niño XXX, y a pesar de no haber consentido tal inseminación, Javier reconoció a XXX como su primogénito. Sin embargo, mucho tiempo después Javier impugnó la paternidad; conoce el juez segundo de familia del Circuito judicial de Bogotá, quien luego de practicada la prueba de ADN y agotadas las etapas de rigor, dictó sentencia acogiendo las pretensiones de Javier, lo que originó que la Autoridad Administrativa, en este caso el defensor de familia, interpusiera recurso contra tal decisión, la cual fue confirmada por el Tribunal Superior de Bogotá. El defensor de familia, invocando el interés superior y la prevalencia de los derechos de los niños, puso de presente que el juez no podía dictar sentencia de impugnación hasta tanto no vinculara al padre biológico del niño XXX, con el fin de no vulnerar el derecho fundamental de filiación de este. Al respecto manifestó:

[...] en el presente caso no se justifica que a estas alturas de los avances planteados, al desatar un litigio de impugnación de paternidad, la Juez de conocimiento solo se limite a declarar que el demandante no es el padre y no se preocupe por indagar, especialmente a la madre, quién es el padre biológico de un niño que antes pasaba por ser hijo de quien en realidad no lo era, actitud que consideró contraria al derecho que el accionado tiene de conocer [a] su padre y así definir su verdadero estado civil ante la familia, la sociedad y el Estado. ${ }^{52}$

Esta lucha entre la autoridad administrativa, el juez y ahora el Tribunal, en relación con el derecho de filiación del niño XXX, fue dirimida por la Corte Suprema de Justicia, Sala Civil, corporación que desenvolvió la controversia a favor de las dos primeras instancias judiciales y construyó un concepto jurídico prescribiendo dos postulados: primero, que es evidente que en el presente proceso no fue posible vincular al presunto padre biológico del menor accionado, por cuanto no aparece acreditado quién fue el donante de la muestra de semen utilizada para la inseminación artificial que se practicó a la señora Janeth; segundo, que el derecho prevalente del menor debe ceder ante el derecho del anonimato del donante; que de la apretada síntesis del tratamiento jurídico que en el derecho comparado se da sobre la materia, se puede resaltar, en primer término que, en general, tratándose de inseminación artificial heteróloga prevalece la confidencialidad del donante sobre el principio de la 
verdad biológica. En este caso se privilegió el derecho del adulto que había reconocido al niño y no el derecho de la filiación de este.

En el 2013 se presentó otro caso interesante entre una reclusa que estaba en estado de embarazo y el derecho del Estado colombiano a extraditarla a los Estados Unidos; en esta oportunidad la lucha fue entre el ICBF y la justicia administrativa: el Consejo de Estado niega el derecho del niño que está por nacer a permanecer por tres años al lado de su madre, en el entendido de que los derechos de aquel no son absolutos sino relativos. Los hechos son los siguientes: Clara está privada de la libertad por los delitos de tráfico de drogas, situación que ha generado que las autoridades norteamericanas la soliciten en extradición al Estado colombiano. Ella está en estado de embarazo y con riesgo de aborto, situación que la lleva a solicitar al Instituto Nacional Penitenciario y Carcelario (INPEC), que le conceda el beneficio de detención domiciliaria, que este se extienda a seis meses después del parto y que se le adecúe una celda para que su bebé permanezca a su lado hasta la edad de tres años, teniendo en cuenta que así lo señalan las normas carcelarias, y porque el niño necesita tener una familia y su derecho es prevalente.

La petición le fue negada, lo que dio lugar a que Clara presentara una tutela contra el INPEC y otras autoridades. El ICBF, como coadyuvante, pidió que fueran tutelados los derechos de aquella, con fundamento en que los niños tienen derecho a tener una familia, y este derecho es prevalente. El Tribunal Administrativo amparó el derecho parcialmente: ordenó al INPEC proveer lo necesario para que Clara permaneciera con su hijo en los seis meses siguientes al nacimiento, pero le negó el derecho de permanecer por tres años con su bebé. La providencia fue impugnada por el ICBF con el argumento de que el futuro hijo de la actora tenía derecho a una familia y a no ser separado de ella, por lo cual era pertinente que estuviera con la madre, por lo menos en sus tres primeros años de vida.

El Consejo de Estado conoció en segunda instancia y resolvió la controversia precisando que:

[...] los derechos de los niños tienen el carácter de intangibles y prevalentes, toda vez que no pueden ser suspendidos ni siquiera en las circunstancias más graves y están por sobre los derechos de los demás. La aludida prevalencia e 
intangibilidad no implica que los derechos de los niños sean absolutos y que, por ende, siempre primen por los derechos y obligaciones de los demás. ${ }^{53}$

Y concluyó prescribiendo que si bien los derechos de los niños son prevalentes, lo cierto es que no son absolutos; por lo tanto, deben ser razonablemente armonizados con obligaciones de orden superior, como las que implican las relaciones internacionales. En consecuencia, Clara solo permanecerá los primeros seis meses con su bebé y luego debe ser extraditada a los Estados Unidos. En este caso se priva, por tal concepto, el derecho a tener una familia al que está por nacer.

Este conjunto de posiciones, normas y agentes que muestran los casos citados constituye un verdadero campo jurídico de enfrentamiento, el cual está dotado de reglas de juego que orientan la actividad de los contendientes (operadores del proceso administrativo, defensores de familia, comisarios de familia y jueces) en su lucha por imponer su rol sobre los otros.

Por otra parte, encontramos otros ejemplos de situaciones en que en un mismo espacio territorial concurren dos o más agentes a la hora de determinar quién es el competente para conocer del proceso de restablecimiento del derecho de un niño o niña, quién el competente para tomar la medida, quién instaura la demanda de investigación de paternidad o alimentos, por mencionar solo algunos ejemplos relacionados con este proceso. Por lo tanto, el procedimiento administrativo de definición de competencia termina siendo el objeto de discusión, antes que restablecer los derechos del infante.

En este juego de roles, tensiones y posiciones jurídicas entre agentes están, por supuesto, los abogados ${ }^{54}$, quienes piensan más en su interés particular que en la responsabilidad social que tienen cuando en un proceso está de por medio un niño o niña, como sucede, por ejemplo, en los procesos de adopción de estos por parte de ciudadanos extranjeros. Es bien conocida la presteza de los abogados en cuanto a establecer los términos y dictar sentencia, en lugar de detenerse a analizar las características de la familia

53 Colombia. Consejo de Estado. Sala de lo Contencioso Administrativo, Sección Cuarta. Sentencia de tutela 2 de mayo de 2013. Radicado: 25000-41-000-2013-00297-01 (AC).

54 Juan Ramón Capella, Elementos de análisis jurídico, 5ª ed., Editorial Trotta, Madrid (2008). 
adoptante, la cultura del país donde vivirá el niño o niña y si el sistema de dicho Estado permite hacer seguimiento a la familia que lo acoge en el extranjero ${ }^{55}$.

Otro ejemplo en esta lucha de agentes es la de los académicos que se disputan la oportunidad de imponer verdades descalificando al otro, sin que muchas veces afloren los argumentos de la tesis defen$\operatorname{dida}^{56}$. En palabras de Moreno y Ramírez, la lucha entre agentes especializados es por el monopolio para decir qué es derecho ${ }^{57} \mathrm{y}$ por acumular la mayor cantidad de capital jurídico ${ }^{58}$.

¿Qué se encuentra? Que en el campo de la distribución de las competencias la intervención de los unos choca con la de los otros. Los distintos actores luchan por el privilegio de la verdad en el derecho de infancia, de cómo este se aplica y qué falencias tiene. Abogados, defensores, comisarios, jueces, docentes, académicos y personas que ocupan una posición de respeto o de poder ${ }^{59}$ compiten entre sí para determinar cuál es la autoridad que, en última instancia, decide qué es derecho de infancia, pero no por una mayor eficiencia ni eficacia jurídica, y menos por una justicia social en materia de derechos de los niños y niñas.

Otros agentes que se distinguen en el campo son los que denomino "los inamovibles" 60 , es decir, los que diseñan y ejecutan la política pública de infancia; cada uno sabe dónde está ubicado en el SNBF y asume que a su lugar o espacio va ligado el concepto de pertenencia, visión que desvirtúa su funcionamiento y, especialmente, sus objetivos, dado que no opera desde lo integral y sistemático, sino desde lo sectorial. La política se impone a nivel nacional, muchas veces $\sin$ consultar la realidad local y sin un enfoque ${ }^{61}$ poblacional, territorial, de género, de derechos. Resultado: la entidad territorial la desconoce por no corresponder a sus necesidades. La lucha, entonces, se da entre lo que quieren imponer las autoridades del

55 Colombia. Corte Constitucional. Sentencia T-811 de 2011.

56 Galvis Ortiz, óp. cit., 191.

57 Tejeiro López, óp. cit., 40.

58 Álvaro Moreno Durán \& José Ernesto Ramírez, óp. cit., 35.

59 Bourdieau, óp. cit., 64.

60 Departamento Nacional de Planeación - Instituto Colombiano de Bienestar Familiar - Ministerio de Educación Nacional - Ministerio de la Protección Social. Guías para Alcaldes, Marco para las políticas públicas y lineamientos para la planeación del desarrollo de la infancia y la adolescencia en el municipio, $2^{\mathrm{a}}$ ed., Autores, Bogotá (2008).

61 Aroldo Quiroz Monsalvo, Manual Derecho de Infancia y Adolescencia: aspectos sustanciales y procesales, $2^{\text {a }}$ ed., Ediciones Librería del Profesional, Bogotá (2009). 
centro y lo que realmente requiere la periferia, lo que necesitan los municipios. Las consecuencias son una serie de programas asistencialistas y alcaldes con la canastita para ver "quién me da más".

Mostrado este panorama, ¿cómo funciona el campo? La respuesta la encontramos en los habitus jurídicos ${ }^{62}$ que se presentan en el espacio social y generan la cultura jurídica. Estos pueden ser objetivamente adaptados a los fines sin presuponer una dirección consciente, o sin necesidad de una maestría expresa en las operaciones necesarias para conseguirlos. Además, sumados, pueden ser colectivamente orquestados sin la acción de un director, v. gr., utilizar el tráfico de influencias para beneficiarse como abogado independiente del interés del niño (lo que importa son los "honorarios"), o adjudicar un programa de atención a los niños solo por interés político, sin importar si la persona beneficiada con el contrato lo hace bien o mal, pues lo que cuenta como fin último es mantener el statu quo.

¿Por qué se mantiene el statu quo en el campo jurídico? Porque lo que importa es el capital simbólico: los agentes jurídicos, como se demostró, construyen discursos y replantean nuevos objetivos y estrategias. Es frecuente escuchar: "el Código fracasó, hay que reformarlo", "Tenemos que crear un nuevo sistema penal para adolescentes", "Hay que rebajar la edad penal del niño", "Es urgente aumentar las penas" "63, razones todas fundamentadas en que las soluciones sociales se resuelven con nuevas normas y modificando la política pública de infancia.

Mientras los actores en el campo jurídico libran su batalla, los derechos de infancia se desvanecen entre la pobreza de una alta población del país y la opulencia de unos pocos. Según el Departamento Nacional de Estadística (DANE), para el 2008 la pobreza fue del $46 \%$ y la indigencia subió a 17,8\%, es decir, 2,2 millones de pobres y 7,9 millones de indigentes ${ }^{64}$. Si el $41 \%$ de la población colombiana es menor de 18 años de edad, haciendo la conversión, se tienen 8,2 millones de niños pobres y 3,2 millones de niños en la

62 Álvaro Moreno Durán \& José Ernesto Ramírez, óp. cit., 38.

63 Colombia. Congreso de la República. Ley 1453 de 2011.

64 El Tiempo. Bogotá D.C. 25 de agosto de 2009. 
indigencia, mientras el sector financiero, en solo los dos primeros meses de 2009, había ganado 1,21 billones de pesos ${ }^{65}$.

Lo anterior queda legitimado por lo que Bourdieu denominó habitus, en el sentido que indican Moreno y Ramírez ${ }^{66}$, esto es, una especie de operador de cálculo inconsciente que nos permite orientarnos correctamente dentro de un espacio social, sin necesidad de reflexionar sobre dicha orientación; las múltiples informaciones que reciben los agentes de otros agentes les permiten mantenerse en el convencimiento de lo que dicen y de lo que hacen.

Por otra parte, en el campo jurídico del derecho de infancia local concurre ahora otro factor: el derecho global de infancia, acompañado por los agentes internacionales, quienes también impondrán sus conceptos sobre lo local, que no tendrá opción distinta a ceder ${ }^{67}$, máxime si se tiene en cuenta que el derecho local está regulado por una pluralidad de ordenamientos jurídicos interrelacionados y distribuidos socialmente de varias maneras ${ }^{68}$, a lo cual no escapa el derecho de infancia. Es decir, en un mismo espacio confluye más de un sistema jurídico: el local, el nacional y el transnacional, lo que ha dado como consecuencia que las posiciones jurídicas foráneas se acepten como verdades absolutas en las que se refleja el habitus.

El derecho global de los derechos humanos, y especialmente el referente a los derechos de infancia, se interrelaciona con el derecho nacional. Inclusive, el actual contenido del artículo 44 de la Carta Política señala que los derechos fundamentales de los niños "gozarán también de los demás derechos consagrados en la Constitución, en las leyes y en los Tratados Internacionales ratificados por Colombia" [subrayas añadidas], incorporando así el bloque de constitucionalidad al ordenamiento jurídico en materia de derechos humanos de infancia y adolescencia, las resoluciones que expida Naciones Unidas en relación con la protección de esta población, al igual que los pronunciamientos y recomendaciones del Comité de Derechos del Niño de Naciones Unidas. En consecuencia, al

65 El Tiempo. Bogotá D.C. 3 de abril de 2009.

66 Álvaro Moreno Durán \& José Ernesto Ramírez, óp. cit., 47.

67 García Méndez, óp. cit.

68 Boaventura de Sousa Santos, La Globalización del Derecho. Los nuevos cambios de la regulación y la emancipación, Universidad Nacional de Colombia, Instituto Latinoamericano de Servicios Legales Alternativos, ILSA, Bogotá (1999). 
campo del derecho de infancia local también concurre el derecho global de infancia.

En conclusión, como lo ha señalado la Corte Constitucional, los niños han concentrado la atención de los Estados y de los organismos internacionales que han consagrado en diversos instrumentos de derecho internacional su protección especial por parte de la familia, la sociedad y el Estado, atendiendo la falta de madurez, vulnerabilidad e indefensión, la necesidad de garantizarles un proceso de formación o desarrollo en condiciones adecuadas, teniendo en cuenta que los niños representan el presente del país ${ }^{69}$.

69 Colombia. Corte Constitucional. Sentencia C-228 de 2008. 


\section{CONCLUSIONES}

La sociología que permite estudiar el campus jurídico propuesto por Bourdieu, aplicada al derecho de infancia en Colombia, nos muestra la lucha que se da por parte de los diferentes actores o agentes que lo integran por imponer sus discursos y legitimarlos para convertirlos en verdades absolutas que se repiten irreflexivamente. En este orden de ideas, la sociología jurídica pone al descubierto que el derecho dogmático es mero instrumento formal pre-construido, un objeto que permite señalar que todavía hay mucho por investigar.

El campus jurídico revela la construcción de prácticas arraigadas y vernáculas que se presentan en el derecho de infancia en nuestro país y que son vistas como verdades dentro de la organización social, que se rige por normas y reglas jurídicas que se imponen, y algunas que se consideran supuestas. Por lo tanto, el campo jurídico pone al descubierto dichas prácticas.

La metodología propuesta evidencia que en el campo del derecho de infancia confluye tal derecho con sus propios agentes, su propia estructura y normatividad, y en especial un habitus particular que legitima los discursos de los agentes.

Por otra parte, el campo jurídico muestra como algunos actores quieren construir normas para la protección de los derechos de los niños, en tanto que otros están empecinados en reformarlos desconociendo los avances y progresividad en la garantía de los derechos de la infancia y la adolescencia.

En el campo no solamente concurren los actores locales, también los actores de carácter internacional intervienen en el proceso de diseño de las normas y las políticas públicas, a través de la imposición de reglas sobre el derecho de infancia y adolescencia.

Este texto deja algunos interrogantes por resolver: cómo operan las prácticas de los agentes de las ciencias económicas; las ciencias médicas de la Piedrahíta, los psicólogos, los agentes de la prensa; y cómo se articulan los discursos de estas ciencias con relación a los niños. Presumo que esta investigación es el punto de partida para reflexionar sobre las prácticas de los derechos de la infancia. 


\section{REFERENCIAS}

\section{Doctrina}

Álvaro Moreno Durán \& José Ernesto Ramírez, Sociología del campo jurídico en Colombia: relaciones y perspectivas, Universidad Santo Tomás, Bogotá (2011).

Boaventura de Sousa Santos, La globalización del derecho. Los nuevos cambios de la regulación y la emancipación, Universidad Nacional de Colombia, Instituto Latinoamericano de Servicios Legales Alternativos, ILSA, Bogotá (1999).

Carlos Tejeiro López, Teoría general de niñez y adolescencia, Universidad de los Andes, Bogotá (2005).

Departamento Nacional de Planeación - Instituto Colombiano de Bienestar Familiar - Ministerio de Educación Nacional - Ministerio de la Protección Social. Guías para Alcaldes, Marco para las políticas públicas y lineamientos para la planeación del desarrollo de la infancia y la adolescencia en el municipio, 2 ed., Autores, Bogotá (2008).

Eduardo Bustelo, El recreo de la infancia: argumentos para otro comienzo, Siglo Veintiuno Editores, Buenos Aires (2007).

Emilio García Méndez, Infancia, ley y democracia: una cuestión de justicia, Editorial Temis - Ediciones Depalma, Bogotá - Buenos Aires (1998)

Fabio Sánchez, Las cuentas de la violencia. Ensayos económicos sobre el conflicto y el crimen en Colombia, Editorial Norma, Bogotá (2007).

Inés M. Weinberg, Convención sobre los derechos del niño, Rubinzal-Culzoni Editores, Buenos Aires (2002).

Jean Jacques Rousseau, El contrato social, Editoriales S.A., Madrid (1983).

José Juan Moreso \& Pablo Eugenio Navarro, Orden jurídico y sistema jurídico: una investigación sobre la identidad y la dinámica de los sistemas jurídicos, Centro de estudios constitucionales, Madrid (1993).

Juan Ramón Capella, Elementos de análisis jurídico, 5ª ed., Editorial Trotta, Madrid (2008).

Ligia Galvis Ortiz, Las niñas, los niños y los adolescentes "titulares activos de derechos", Ediciones Aurora, Bogotá (2006).

Mauricio García Villegas \& César Rodríguez, Derecho y sociedad en América Latina: un debate sobre los estudios jurídicos críticos, Editorial ILSA - Universidad Nacional de Colombia, Bogotá (2003).

Rafael Hernández Marín, Introducción a la teoría de la norma jurídica, 2ª ed, Marcial Pons, Ediciones Jurídicas y Sociales S.A., Madrid (2002).

Ricardo Guastini, Distinguiendo: estudios de teoría y metateoría del derecho, Jordi Ferreri Beltrán (trad.), Editorial Gedisa, Barcelona (1999).

Sistema de las Naciones Unidas \& CePAL. Programa Nacional de Desarrollo Humano DNP/PNUD - Agencia Colombiana de Cooperación Internacional - Federación Colombiana de Municipios y Cooperación Técnica Alemana GTZ, Las regiones colombianas frente a los objetivos del milenio, Autores, Bogotá (2004). 


\section{Normativa nacional}

Código de la Infancia y la Adolescencia. Ley 1098 de 2006. 08 de noviembre de 2006. D.O. No. 46446

Constitución Política de Colombia [Const.]. 7 de julio de 1991 (Colombia).

Departamento Administrativo de la Prosperidad Social. Decreto 0936. Por el cual se reorganiza el Sistema Nacional de Bienestar Familiar, se reglamenta el inciso primero del artículo 205 de la Ley 1098 de 2006 y se dictan otras disposiciones. 9 de mayo de 2013. D.O. No. 48.786.

Ley 1453 de 2011. Por medio de la cual se reforma el Código Penal, el Código de Procedimiento Penal, el Código de Infancia y Adolescencia, las reglas sobre extinción de dominio y se dictan otras disposiciones en materia de seguridad. 24 de junio de 2011. D.O. No. 48110.

Ley 7 de 1979. Por la cual se instituye el Sistema Nacional de Bienestar Familiar. 24 de enero de 1979. D.O. No. 35.191.

Ley 75 de 1968. Por la cual se dictan normas sobre filiación y se crea el Instituto Colombiano de Bienestar Familiar. 30 de diciembre de 1968. D.O. No. 32.682.

Presidencia de la República. Decreto 2737 de 1989. Por el cual se expide el Código del Menor.

Senado de la República. Proyecto de Ley No. 164 de 2010. Por medio de la cual se reforma el Código Penal, el Código de Procedimiento Penal, el Código de Infancia y Adolescencia; las reglas sobre extinción de dominio y se dictan otras disposiciones en materia de seguridad ciudadana.

\section{Jurisprudencia nacional}

Consejo de Estado. Sala de lo Contencioso Administrativo, Sección Cuarta. Sentencia de tutela 2 de mayo de 2013. Radicado: 25000-41-000-2013-00297-01 (AC).

Corte Constitucional. Sentencia C-228 de 2008 (M. P. Jaime Araújo Rentería).

Corte Constitucional. Sentencia T-071 de 2001 (M. P. Jorge Iván Palacio Palacio).

Corte Constitucional. Sentencia T-811 de 2011 (M. P. Mauricio González Cuervo).

Corte Constitucional. Sentencia T-968 de 2009 (M. P. María Victoria Calle Correa).

\section{Artículos de prensa}

El Tiempo, "La corrupción de las regalías en Casanare", pp. 1, 3 (11 de junio de 2009).

El Tiempo, "La pobreza en Colombia”, pp. 1, 8 (25 de agosto de 2009).

El Tiempo, "Los ingresos del sector financiero", pp. 1, 11 (3 de abril de 2009). 


\section{Documentos electrónicos}

Fondo de las Naciones Unidas para la Infancia, Algunos ejemplos de indicadores sobre: ciclo vital. Disponible en www.sinfoniaunicef.info/category/ciclo-vital/ (recuperado el 28 de marzo del 2014). 
